\title{
Seasonal modulation of the C-type lectin MGL on human DCs
}

\author{
Ilaria Grazia Zizzari, Chiara Napoletano*, Aurelia Rughetti, Hassan Rahimi, Marianna Nuti
}

Department of Experimental Medicine, "Sapienza” University of Rome, Rome, Italy;

*Corresponding Author: chiara.napoletano@uniroma1.it

Received 19 September 2013; revised 19 October 2013; accepted 26 October 2013

Copyright (C) 2013 Ilaria Grazia Zizzari et al. This is an open access article distributed under the Creative Commons Attribution License, which permits unrestricted use, distribution, and reproduction in any medium, provided the original work is properly cited. In accordance of the Creative Commons Attribution License all Copyrights (C) 2013 are reserved for SCIRP and the owner of the intellectual property Ilaria Grazia Zizzari et al. All Copyright (C) 2013 are guarded by law and by SCIRP as a guardian.

\begin{abstract}
The C-type lectin MGL is a pathogen recognition receptor, expressed by dendritic cells (DCs) and macrophages $(\mathrm{M} \phi \mathrm{s})$, able to bind GalNAc (Tn)carrying structures. This receptor also recognized Tn-TAAs that were internalized, processed and presented by DCs to T cells and it acted as an adjuvant on DCs, highlighting its possible application in anti-cancer vaccination. In this work, we found that this receptor present a seasonal modulation: its expression is higher in winter rather than in summer. The percentage of $\mathrm{MGL}^{+}$ donors displayed a negative trend that dropped to $33 \%$ during the summer and increased up to $100 \%$ in winter. This modulation could be also ascribed to the circa-annual variation of glucocorticoids, in fact MGL is up-regulated in presence of dexamethasone in vitro. The seasonal variation of this receptor could be an important point in the field of tumor vaccination strategies.
\end{abstract}

Keywords: MGL; Dendritic Cells; C-Type Lectin

\section{INTRODUCTION}

Dendritic cells (DCs) are the most important antigen presenting cells (APCs) and, acting as sensors of microenvironment, capture pathogens and transmit the resulting information to lymphocytes. These activities can be carried out thanks to several types of highly specialized receptors such as C-Type Lectin Receptors (CLRs) and Toll like Receptors (TLRs) that are expressed on DC surface [1]. CLRs' family acts in $\mathrm{Ca}^{2+}$-dependent manner [2], is able to bind and internalize carbohydrate structures and finally can induce the activation of $\mathrm{T}$ lymphocytes. Thanks to these properties CLRs are considered targets to enhance $\mathrm{T}$ cell-mediated protective immunity to prevent infectious diseases. Human MGL (Macrophage Galactose type C-type Lectin) is a C-type lectin expressed by immature myeloid Dendritic Cells (iDCs) and macrophages $(\mathrm{M} \phi \mathrm{s})$, able to bind the N-Acetyl-Galactosamine residues (GalNAc or Tn). Any glycolipid, glycoprotein and pathogen carrying GalNAc is recognized and internalized by MGL expressing cells, thus including MGL in the list of Pathogen Recognition Receptors (PRRs) [3].

In the last years, it has been extensively demonstrated the involvement of this receptor in the uptake and processing of Tn-Tumor Associate Antigens (Tn-TAAs) [4,5]. In fact, MGL engagement acts as an adjuvant on DCs, promoting a phenotypic and functional maturation of the cells [4] and inducing Tn-TAAs cross-presentation [5]. The ability of MGL to stimulate the maturation of DCs and to induce a strong $\mathrm{CD} 8^{+} \mathrm{T}$ cell activation highlights the possibility to use this receptor as a target for anticancer vaccination.

Here we report the results obtained monitoring the expression of human MGL throughout a year on monocytes-derived DCs, in order to understand the optimal timing of MGL expression in DCs-based vaccination, with the purpose to use MGL as a vehicle for the delivery of Tn-TAAs.

\section{MATERIALS AND METHODS}

\subsection{Generation}

Peripheral Blood Mononuclear Cells (PBMCs) were isolated by Ficoll-Hypaque gradient $(1077 \mathrm{~g} / \mathrm{mL}$; Pharmacia LKB, Uppsala, Sweden). Monocytes (CD14 $\left.{ }^{+}\right)$ were purified by CD14 MicroBeads (Miltenyi Biotech, Paris, France) and cultured $\left(5 \times 10^{5}\right.$ cells $\left./ \mathrm{mL}\right)$ in RPMI 1640 (Hyclone, UT, USA) supplemented with 2 mMLgluta-mine (Sigma Chemical Company, St. Louis, MO, USA), penicillin $100 \mathrm{U} / \mathrm{mL}$ (Sigma), streptomycin 100 
$\mu \mathrm{g} / \mathrm{mL}$ (Sigma) with $10 \%$ heat-inactivated Fetal Calf Serum (Hyclone). A total of $50 \mathrm{ng} / \mathrm{mL}$ rhGM-CSF (R \& D System, Minneapolis, MN) and $1000 \mathrm{U} / \mathrm{mL}$ rhIL-4 (R \& D System) were added at day 0 and 2. iDCs were collected at day 5 .

\subsection{Phenotype}

Cell phenotype staining was performed using the following antibodies: MoAbs anti-hMGL (ASGPR/MGL, 125A10.03 clone, Dendritics, Lyon, France) followed by FITC-conjugated goat anti-mouse $\operatorname{IgG}(\mathrm{H}+\mathrm{L})$ (Jackson ImmunoResearch Laboratories, West Grove, PA, USA). MoAbs directly conjugated with FITC or phycoerythrin (PE) were also employed: IgG-FITC and -PE as isotype controls, anti-HLAII-DR-FITC, anti-CD86-FITC, antiCD83-PE, anti-CD40-PE, anti-CD14-PE all from Becton Dickinson (San Diego, CA, USA) and anti-CCR7-FITC from R\&D. DCs were incubated with conjugated-MoAb for $30 \mathrm{~min}$ at room temperature (RT) as indicated by the manufacturer's instruction. After washing, at least $1 \times$ $10^{4}$ events were evaluated using a FACSCanto flow cytometer running FACSDiva acquisition and data analysis software (Becton Dickinson).

\section{RESULTS}

We monitored the MGL expression on iDCs derived from 144 healthy donors throughout a year (12 donors/ month). Monocytes were differentiated for 5 days in iDCs (Figure 1(a)) and the presence of the receptor was analysed by cytofluorimetry. The results obtained showed that MGL expression on iDCs surprisingly had a seasonal modulation: the expression was higher in winter rather than in summer, despite that yield and quality of DCs were homogeneous. Figure 1(b) shows the expression of MGL as fold increase, obtained by the ratio between the Mean Fluorescence Intensity (MFI) of DCs stained with an anti-MGL antibody and the MFI obtained by the addition of the isotype control. We considered $\mathrm{MGL}^{+}$donors all those samples that showed at least a two fold increase. As described in Figure 1(c), MGL expression among donors displayed a negative linear trend going from the winter (100\% in January; $50 \%$ in March) to the spring dropping to $33 \%$ during the summer period. The percentage of $\mathrm{MGL}^{+}$donors began to increase in September (58\%) reaching the $83 \%$ at the end of the year (December).

\section{DISCUSSION}

In this report we showed for the first time a circa-annual rhythm of human MGL receptor on iDCs. Its expression was higher in winter rather than in summer, as well as several C-Type Lectins expressed by other organisms such as plants [6].

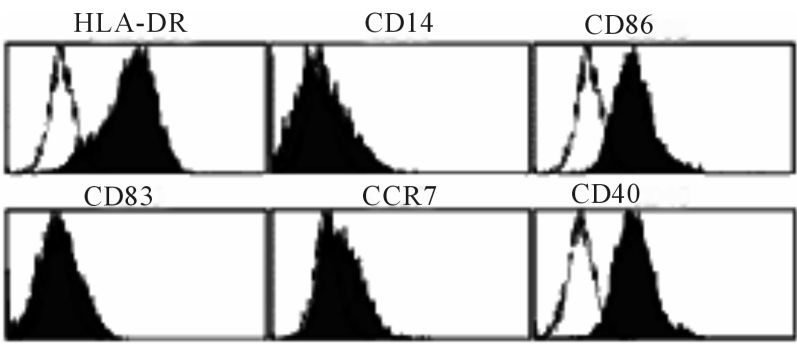

(a)

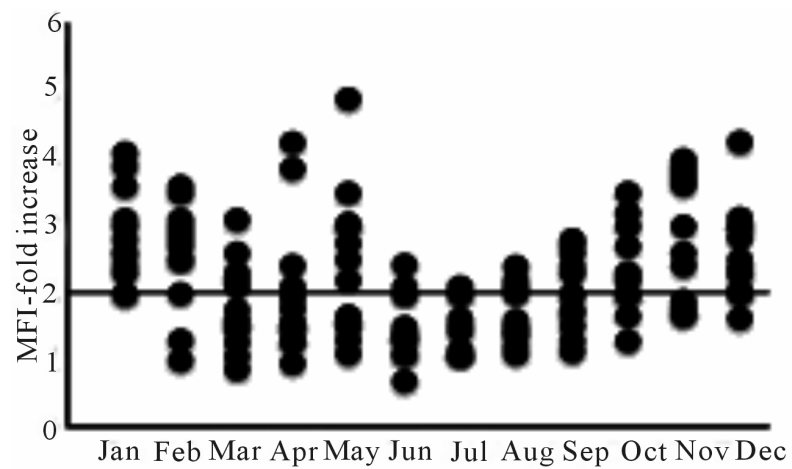

(b)

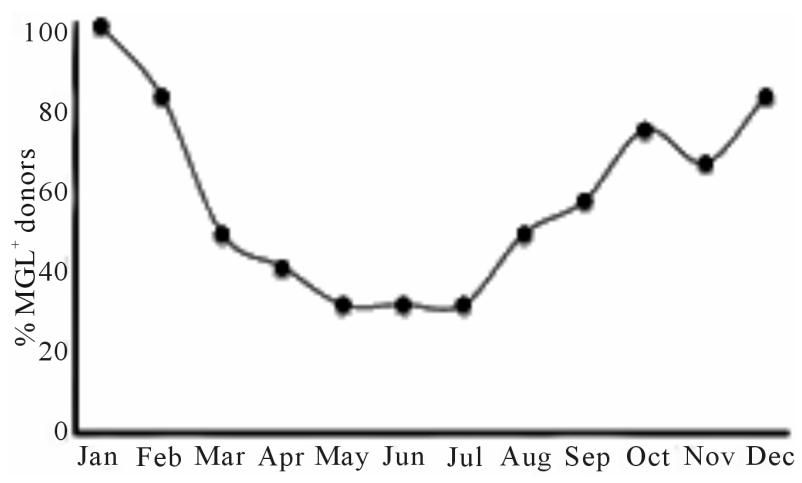

(c)

Figure 1. Expression and modulation of the MGL receptor on DCs: (a) iDC phenotype at day 5 of differentiation analyzed by cytofluorimetry. The empty histograms represent the isotype control. The panel shows a representative donor; (b) MGL expression evaluated by cytofluorimetry adding an anti-MGL antibody (125A10.03 clone) or the IgG1 isotype control to the iDCs followed by Fluorescein Isothiocyanate (FITC)-conjugated goat anti-mouse $\operatorname{IgG}(\mathrm{H}+\mathrm{L})$. For each donor, MGL expression was reported as fold increase of the MFI obtained with the anti-MGL antibody / MFI of the isotype control. All donors with a ratio $\geq 2$ were considered $\mathrm{MGL}^{+}$; (c) Percentage of $\mathrm{MGL}^{+}$donors throughout a year.

MGL represented an exclusive marker of myeloid iDCs and it has been demonstrated in vitro that its expression was increased by dexamethasone (Dex) treatment [7]. Up to now little is known on the factors that can modulate the circa-annual rhythm of the human lectins $[6,8]$ on DCs, but extensively studies on the impact of glucocorticoids (GCs) like Dex on DCs were conducted. Rea D. et al. showed that Dex affected the 
viability of DCs, selectively down-regulated the expression of costimulatory molecules reducing their immunostimulatory properties [9]. Moreover in vivo studies showed that a single injection of Dex impaired DC antigen presentation [10]. These results indicated that GCs regulated the DC maturation and immune functions in vitro and in vivo, demonstrating that GCs played a role in the prevention of spontaneous activation of DCs, decreasing their T-cell stimulatory potential and influencing the expression of molecular markers, such as MGL. Furthermore GCs in human seemed to have per se a seasonal modulation [11], that was similar to that observed for MGL. These variations were probably due to the stress-related factors that were differently released during the year. These evidences prompted us to believe that GCs could be one of the possible factors that contribute to MGL circa-annual rhythm.

Interestingly, similar seasonal modulation has been demonstrated for other PRRs, such as TLR (Toll-like Receptor)-2 and -4. Their expression on PBMCs was shown to be seasonally modulated by blood circulating Vitamin $\mathrm{D}_{3}$ resulting in the secretion of distinct cytokine patterns that contribute to alter the innate immune response [12].

The modulation of MGL on DCs as well as of other PRRs might be due to seasonal changes of immune system probably characterized by several molecular mechanisms contributing to the response of immune system to the seasonal stress stimuli, even if further studies need to be performed in order to identify all the processes implicated in this phenomenon. Since MGL is a PRR with the capacity to internalize its ligands and has adjuvant effects on DCs, this modulation can have important implications in the planning of vaccines against pathogens as well as in the identification of the optimal timing for DCs-based vaccination in cancer patients.

\section{ACKNOWLEDGEMENTS}

This work was supported by Ministero per l'Istruzione e la Ricerca Scientifica (AR: PRIN 2009NREAT2_004, MN: PRIN 2009XMZPKW), AIRC IG2009, "Sapienza", Università di Roma and Ministero della Salute (AR, MN, CN: C26AI2L3RA).

\section{REFERENCES}

[1] van Vliet, S.J., García-Vallejo, J.J. and van Kooyk, Y. (2008) Dendritic cells and C-type lectin receptors: Coupling innate to adaptive immune responses. Immunology and Cell Biology, 86, 580-587.

http://dx.doi.org/10.1038/icb.2008.55

[2] Zelensky, A. N. and Gready, J. E. (2005) The C-type lectin-like domain superfamily. FEBS Journal, 272, 6179-6217. http://dx.doi.org/10.1111/j.1742-4658.2005.05031.x

[3] van Vliet, S.J., van Liempt, E., Saeland, E., Aarnoudse, C.A., Appelmelk, B., Irimura, T., Geijtenbeek, T.B., Blixt,
O., Alvarez, R., van Die, I. and van Kooyk, Y. (2005) Carbohydrate profiling reveals a distinctive role for the C-type lectin MGL in the recognition of helminth parasites and tumor antigens by dendritic cells. International Immunology, 17, 661-669. http://dx.doi.org/10.1093/intimm/dxh246

[4] Napoletano, C., Zizzari, I.G., Rughetti, A., Rahimi, H., Irimura, T., Clausen, H., Wandall, H.H., Belleudi, F., Bellati, F., Pierelli, L., Frati, L. and Nuti, M. (2012) Targeting of macrophage galactose-type C-type lectin (MGL) induces DC signaling and activation. European Journal of Immunology, 42, 936-945. http://dx.doi.org/10.1002/eji.201142086

[5] Napoletano, C., Rughetti, A., Tarp, M.P.A., Coleman, J., Bennett, E.P., Picco, G., Sale, P., Denda-Nagai, K., Irimura, T., Mandel, U., Clausen, H., Frati, L., Taylor-Papadimitriou, J., Burchell, J. and Nuti, M. (2007) Tumorassociated Tn-MUC1 glycoform is internalized through the macrophage galactose-type C-type lectin and delivered to the HLA class I and II compartments in dendritic cells. Cancer Research, 67, 8358-8367. http://dx.doi.org/10.1158/0008-5472.CAN-07-1035

[6] Yoshida, K., Baba, K., Yamamoto, N. and Tazaki, K (1994) Cloning of a lectin cDNA and seasonal changes in levels of the lectin and its mRNA in the inner bark of Robinia pseudoacacia. Plant Molecular Biology, 25, 1010-1017. http://dx.doi.org/10.1007/BF00028879

[7] van Vliet, S.J., van Liempt, E., Geijtenbeek, T.B. and van Kooyk, Y. (2006) Differential regulation of C-type lectin expression on tolerogenic dendritic cell subsets. Immunobiology, 211, 577-585. http://dx.doi.org/10.1016/j.imbio.2006.05.022

[8] Lévi, F.A., Canon, C., Touitou, Y., Reinberg, A. and Mathé, G. (1988) Seasonal modulation of the circadian time structure of circulating $\mathrm{T}$ and natural killer lymphocyte subsets from healthy subjects. Journal of Clinical Investigation, 81, 407-413.

http://dx.doi.org/10.1172/JCI113333

[9] Rea, D., van Kooten, C., van Meijgaarden, K.E., Ottenhoff, T.H., Melief, C.J. and Offringa, R. (2000) Glucocorticoids transform CD40-triggering of dendritic cells into an alternative activation pathway resulting in antigenpresenting cells that secrete IL-10. Blood, 95, 3162-3167.

[10] Moser, M., De Smedt, T., Sornasse, T., Tielemans, F., Chentoufi, A.A., Muraille, E., Van Mechelen, M., Urbain, J. and Leo, O. (1995) Glucocorticoids down-regulate dendritic cell function in vitro and in vivo. European Journal of Immunology, 25, 2818-2824. http://dx.doi.org/10.1002/eji.1830251016

[11] Walker, B.R., Best, R., Noon, J.P., Watt, G.C. and Webb, D.J. (1997) Seasonal variation in glucocorticoid activity in healthy men. The Journal of Clinical Endocrinology \& Metabolism, 82, 4015-4019. http://dx.doi.org/10.1210/jc.82.12.4015

[12] Khoo, A.L., Chai, L.Y., Koenen, H.J., Sweep, F.C., Joosten, I., Netea, M.G. and van der Ven A.J. (2011) Regulation of cytokine responses by seasonality of vitamin D status in healthy individuals. Clinical \& Experimental Immunology, 164, 72-79.

http://dx.doi.org/10.1111/j.1365-2249.2010.04315.x 